\title{
El rol del orientador como agente dinamizador del escenario educativo y social
}

\section{The role of the school counselor as an energizing agent in the educational and social scenario}

\author{
Jesús Morales-Carrero \\ Profesor, Escuela de Criminología \\ Universidad de Los Andes \\ Mérida, Venezuela \\ lectoescrituraula@gmail.com
}

Recibido - Received: 12 / 7 / 2019

Corregido - Revised: 25/ 12 / 2020

Aceptado - Accepted: 21 / 02 / 2020

DOI: https://doi.org/10.22458/ie.v22i32.2903

URL: https://revistas.uned.ac.cr/index.php/innovaciones

\begin{abstract}
Resumen: El rol del profesional de la orientación como agente dinamizador del proceso educativo ha tomado un auge especial en el siglo XXI. Ello motivado porque el escenario educativo al ser el lugar de confluencia de diversas prácticas sociales y culturales, se ha convertido en un espacio saturado de controversias, así como de situaciones problemáticas que ameritan del uso de estrategias de intervención propiciadoras de condiciones oportunas para que el estudiante y los demás actores educativos consigan resolver, bien sea por sí mismo o con la cooperación de terceros, los conflictos personales, emocionales, afectivos, educativos y sociales. En atención a estos requerimientos, se pretende lograr una revisión teórica que deje entrever la relevancia del profesional de la orientación como actor del sistema educativo, capaz de promover el desarrollo multidimensional de los demás participantes a través de la promoción y el aprendizaje de habilidades sociales tales como: actitudes empáticas, la resolución pacífica de controversias, la toma de decisiones y la cooperación como prácticas que por su relevancia favorecen la formación de ciudadanos con un amplio sentido de pertenencia, participación y con la vocación para transformar protagónicamente su realidad y la de otros. Por ende, la función de la persona orientadora debe enfocarse en propiciar los medios para subsistir en condiciones adversas, estrés, frustraciones y ambientes cargados de hostilidad, situaciones conflictivas que por su elevado nivel de recurrencia aquejan al ser humano en la actualidad.
\end{abstract}

Palabras clave: orientador, contexto social, escenario educativo, habilidades sociales, situaciones conflictivas

Summary: The role of the school counseling professional as an energizing agent of the educational process has experienced a special upswing in the 21st century. This has occurred because the educational setting, being the place of confluence of various social and cultural practices, has become a space saturated with controversies, as well as problematic situations. These warrant the use of intervention strategies that promote the appropriate conditions so that the student and the other educational actors are able to resolve, either by themselves or with the cooperation of third parties, personal, emotional, affective, educational and social conflicts. In response to these requirements, it is intended to achieve a theoretical review that hints at the relevance of the schoolcounseling professional as an actor in the educational system. This counselor should be capable of promoting the multidimensional development of other participants through the promotion and learning of social skills such as: empathetic attitudes, the peaceful resolution of controversies, decision-making and cooperation. These are practices that, due to their relevance, favor the formation of citizens with a broad sense of belonging, participation and with the vocation to transform their reality and that of others. Therefore, the role of the counselor should focus on promoting the means to survive in adverse conditions, stress, frustrations and hostile environments, conflictive situations that due to their high level of recurrence afflict the human being today.

Key Words: counselor, social context, educational setting, social skills, conflict situations 


\section{INTRODUCCIÓN}

Orientar como proceso relacionado con el bienestar, la salud integral y el desarrollo humano se ha consolidado en un momento histórico como el siglo XXI en el medio, según Bisquerra (2009), para "asegurar el desarrollo de competencias emocionales que le permitan al individuo responder y enfrentar con éxito las demandas derivadas de las organizaciones, del contexto comunitario y de la sociedad en general" (p.13). Lo expuesto significa que la orientación educativa, como proceso socioeducativo, entraña una elevada responsabilidad social que persigue dentro de sus cometidos, lograr equilibrio personal a través del desarrollo y la realización de las diversas dimensiones que componen al ser humano (Daros, 2009; Rogoff, 1993; UNESCO, 2015).

Las premisas confirman que orientar es un proceso centrado en atender las necesidades de las personas, de resignificar las experiencias, motivar la realización de intereses personales y cooperar con el cumplimiento de propósitos colectivos, aspectos que por su relevancia apuntan a la evolución de todas las dimensiones de lo humano. Orientar es guiar a lo largo de la vida e indicar las posibles alternativas que permitan la autorrealización y el cómo aprender a gestionarse a sí mismo.

Según Bisquerra, se puede entender la orientación (1986) como un proceso de ayuda permanente que se ofrece "a todas las personas, en todos sus aspectos, con objeto de potenciar la prevención y el desarrollo humano a lo largo de toda la vida. Esta ayuda se realiza mediante programas de intervención psicopedagógica, basados en principios científicos y filosóficos" (p. 52). Esta concepción de la orientación coincide con los principios de la educación para la ciudadanía mundial, en la que se pauta como fundamento la atención, dirección y asesoramiento como procesos inherentes al desarrollo humano y a la consolidación de condiciones óptimas que atiendan las necesidades de las etapas de la vida.

Desde esta perspectiva, es posible esgrimir que la orientación como actividad que trasciende el espacio educativo representa una herramienta de intervención que favorece la consolidación de funciones como la adaptación y la socialización; con respecto a la primera, procura la integración de la persona a la dinámica social, a sus roles y funciones; mientras la segunda refiere al aprendizaje de las normas, las reglas morales y las convenciones sociales que rigen su actuación como ciudadano del mundo. Estos propósitos se relacionan con la formación de una persona mediante las competencias necesarias para comportarse de manera independiente y autónoma (Maslow, 1954), cometidos que la educación en la actualidad ha posicionado como elementos necesarios para formar ciudadanos cónsonos con las exigencias sociales.

Atendiendo a las demandas mencionadas, la psicología social ha propuesto la necesidad de promover momentos educativos en los que el estudiante logre interactuar con situaciones reales que le familiaricen con el carácter cambiante de la vida (Freire, 2002), con el propósito de fortalecer su determinación como factor indispensable para integrarse a las relaciones que comúnmente forman parte de la interacción grupal (Barra, 1998; Huici y otros, 2012).

La posición anterior implica utilizar la orientación como mecanismo para promover la participación social, la integración, el respeto y el reconocimiento de las diferencias en un intento por reducir significativamente brechas de desigualdad como las generadoras de discriminación y a las que se les atribuye en mayor o en menor media la alteración de valores como la armonía y el entendimiento a nivel familiar y social. Se trata así, de entender la orientación como una herramienta para el desarrollo de habilidades sociales que propicien, según expone Bisquerra (2009), la práctica de vínculos importantes como "la bondad, la igualdad, la cooperación, la modestia, la hospitalidad y el apoyo a los más débiles" (p. 64).

En este sentido, la orientación persigue, entre otros propósitos, la promoción de actitudes relacionadas con el liderazgo, la interacción grupal y la construcción autónoma de proyectos de vida, procesos que 
por su relevancia y trascendencia se constituyen en medios necesarios para fortalecer la convivencia humana, en la que se establezcan responsabilidades compartidas y el dar o recibir ayuda como condiciones elementales para enfrentar con efectividad los retos que emergen y de los que depende el logro de objetivos comunes. Esta responsabilidad social exige como lo expone Camps (2000) la mediación de actitudes empáticas y colectivas dadas a "la resolución continua de conflictos, de problemas no resueltos y de insatisfacciones emergentes de su propia realidad" (p. 1).

En atención a lo planteado, el ensayo pretende lograr una revisión teórica que deje entrever la relevancia del profesional de la orientación como actor del sistema educativo, a quien se le atribuyen responsabilidades específicas como la promoción y ejecución de acciones educativas, así como el desarrollo de habilidades y competencias sociales que hagan posible la integración y participación autónoma del individuo en el escenario socioeducativo.

\section{EL ROL DEL ORIENTADOR EN EL SIGLO XXI}

Educar para la vida y para el ejercicio protagónico de acciones de intervención social se ha convertido, dentro de los cometidos de la educación del XXI, en un eje transversal que busca la formación de ciudadanos comprometidos, autónomos y responsables. En este sentido, las relaciones de ayuda como parte de las funciones propias de la orientación se han enfocado en la creación de condiciones sociales, culturales y educativas que posibiliten el desarrollo de actitudes independientes, resilentes y competentes como herramientas para enfrentar creativamente los retos, los obstáculos y las adversidades que el contexto impone.

Por tal motivo, el papel del profesional en Orientación ha tomado especial interés por asumirse como un actor educativo capaz de ofrecer las herramientas necesarias que les permitan a los actores del sistema educativo operar con eficiencia en la resolución de situaciones problemáticas relacionadas, según exponen Méndez, Tesoro y Tiranti (2006), con "áreas diferentes de la vida, la contención afectiva en determinados casos, detección de problemas en la dimensión relacional de los miembros del grupo, señalar posibles direcciones en procesos decisorios, y atender puntos focal como lo es la formación en valores" (p. 4).

Al respecto Bordón (2005) propone que el proceso de orientación se encuentra constituido por la confluencia de diversas actividades, entre las que se incluye "atender las demandas de ayuda y formulación de estrategias de cooperación que propicien intervenciones psicopedagógicas factibles y necesarias para la resolución de problemas en el ámbito educativo" (p. 1). En apoyo a esta postura, Bisquerra y Pérez (2007) proponen que el rol de la persona orientadora se circunscribe a la noción de agente de cambio y creador de las condiciones necesarias para el desarrollo personal, social y profesional, capaz de generar procesos de intervención que preparen a los actores del escenario educativo para "adoptar comportamientos apropiados y responsables que les permitan afrontar satisfactoriamente los desafíos de la vida diaria" (p. 11).

Lo anterior, indica que orientar como una función propiamente educativa consiste en generar las condiciones oportunas para que la persona logre resolver situaciones problemáticas vinculadas con las actividades frecuentemente desarrolladas dentro del contexto institucional y aquellos inconvenientes que, por alguna razón no han sido solventados en su escenario familiar, comunitario y social. El nivel de compromiso indica que la orientación logre que los componentes del acto educativo se integren responsablemente al abordaje de situaciones, inconvenientes y necesidades de su espacio inmediato de convivencia, en procura de resolver en los mejores términos situaciones conflictivas de índole histórico-social. 
Por ende, su actuación representa la posibilidad de establecer un rol empático enfocado en el establecimiento de diálogos efectivos que den cabida a procesos comunicativos y relaciones de ayuda que favorezcan la construcción de respuestas y medidas conjuntas entre él como profesional de la orientación y los grupos que tiene a su cargo, aportando desde una mirada multidisciplinaria el abordaje y la intervención de inconvenientes que vayan, según exponen Méndez, Tesoro y Tiranti (2006), "más allá de su especifica actividad docente, hacia el cultivo de la personalidad y el desarrollo del carácter" (p. 6).

Para Corkille (1970), el profesional en Orientación debe asumir funciones que lleven a la persona a manejar sus propias decisiones y "a formar jóvenes confiados en sí mismos, emocionalmente estables, y capaces de vivir como personas que funcionan plenamente y desarrollan existencias significativas, aspectos fundados sobre una estructura básica coherente en lo que respecta a su autoestima" (p.8). Lo anterior significa desarrollar niveles de autonomía emocional para lograr que el orientado se convenza del papel protagónico que debe asumir como constructor de su propio éxito o fracaso, así como entender estos como condiciones para definir su posición frente a la vida (Daros, 2009; Piaget, 2001).

Como consecuencia, la pedagogía crítica se ha enfocado en construir escenarios en los que el ser humano se apropie de las habilidades necesarias para evaluar con responsabilidad las alternativas y opciones más idóneas que le permitan, según expone Corkille (1970), construir su propia identidad como aspectos que le "habilitarán para alcanzar la felicidad personal en todos los órdenes de la vida desde un sólido sentido del valor propio" (p. 8). Como complemento de esta afirmación, Bisquerra (2009) propone que el profesional en Orientación debe ser capaz de desarrollar competencias emocionales y sociales tales como "autoestima, relaciones efectivas, habilidades de vida, automotivación y bienestar" (p. 146).

El compromiso propio de la orientación educativa, implica según Daros (2009) un elevado nivel de sensibilidad en la que el sujeto sea capaz de "revisarse internamente para identificar sus potencialidades intelectuales, afectivas, humanas y sociales desde las cuales accionar sobre la realidad poniendo al servicio de su propio éxito los recursos derivados de la interacción social y de la unificación de esfuerzos" (p.11). Se trata de guiar a quien se orienta a comprender su condición humana y los esfuerzos que debe realizar para sortear los obstáculos y problemas derivados de la convivencia con otros, los cuales deben entenderse como situaciones cuya resolución requiere de la integración de esfuerzos conjuntos y estratégicos por parte de los diversos actores sociales que forman parte de su contexto.

Estas razones demandan que el profesional de la orientación consiga guiar a los participantes del sistema educativo a la comprensión y abordaje de los problemas que generan conmoción y, que por sus repercusiones e implicancias ameritan la realización de ajustes individuales y colectivos que definan comportamientos y actitudes positivas, con el propósito de evitar la erosión de la identidad propia y de los modos de vida, de las creencias y valores que posibilitan la estabilidad social (Galagovsky, 1993; Gardner, 1996; Illich, 1985; Lipovestsky, 2000).

De acuerdo con Rogers (1996) la labor de la persona que orienta debe trascender de "la mera transmisión de conocimiento a la generación joven sobre cómo conducirse para llevarla a crear sus propios medios para subsistir en medio de un ambiente hostil y relativamente estático" (p.6). En tal sentido, orientar debe asumirse como un proceso de atención integral, que posibilita la mediación en la resolución de conflictos personales, condición que requiere la preparación de la persona para enfrentar creativamente los problemas, mediante la exploración y el ofrecimiento de diversas alternativas a partir de las cuales abordar las múltiples vicisitudes que se experimentan cotidianamente.

Lo anterior implica así poner en práctica acciones de asesoramiento que le permitan al ser humano asumir actitudes autónomas, responsables, de exploración guiada, de participación e integración en actividades de indagación y afrontamiento que cooperen con el desarrollo de competencias para responder al cambio recurrente que experimenta el mundo, y ante el cual se espera que su actuación esté caracterizada por el entusiasmo, la motivación y la innovación como condiciones que, desde la 
perspectiva humanista y psicológica, son necesarias para la generación de aprendizajes significativos que favorezcan el abordaje crítico, autónomo y comprometido de situaciones semejantes tanto en el entorno educativo como en el contexto social general.

Lo expuesto puede interpretarse como una estrategia necesaria para vivir y convivir de manera exitosa como requerimiento que le permita al individuo lidiar con la adversidad y la frustración como aspectos que, por su frecuencia, vienen a constituirse en detonantes de la obstinación y la desmotivación. Ante este escenario, la persona que orienta debe proceder de manera activa ofreciendo explicaciones, interpretaciones y razonamientos que muestren su competencia para comprender los múltiples beneficios y consecuencias que se desprenden de los obstáculos y situaciones conflictivas, así como aquellos aspectos positivos que pudieran contribuir con el crecimiento personal (Rogers, 1996).

Se trata por tanto de llevar a quien se orienta a la adquisición de las competencias emocionales adecuadas para enfrentar situaciones complejas que hacen parte de la vida diaria o lo que en palabras de Bisquerra (2009) sería "educarlo emocionalmente para que sea capaz de regular de manera apropiada los retos y las adversidades, para lo cual se hace necesario un entrenamiento intenso para que exprese respuestas controladas y no impulsivas que lo predispongan a accionar en forma correcta" (p. 21).

Por su parte, Maturana (1990) afirma que la educación y la orientación persiguen que el ser humano eduque sus emociones con el objeto de reconocer al otro, ejercer dominio sobre la conducta, promover relaciones de convivencia a través de interacciones recurrentes, positivas y consensuales, así como desarrollar procesos comunicativos que insten a la persona a valerse del diálogo para resolver conflictos, desencuentros y situaciones emergentes como consecuencia de las desigualdades sociales. Al respecto, la educación para a ciudadanía mundial propone que el profesional de la orientación debe ser capaz de cooperar con la resolución de las contradicciones y los cambios que vive el mundo en general, siempre y cuando se deje a un lado el individualismo y se promueva el bienestar colectivo así como la supresión de la exclusión social.

A partir de estos aportes, es posible afirmar que el profesional, como parte de sus atribuciones, cuenta con la promoción y la gestión de comportamientos que propicien la construcción de escenarios democráticos y solidarios, en los que se desarrolle positivamente la personalidad y se logren mayores niveles de participación y de humanización para responder a las convenciones sociales y a los acuerdos de convivencia, máximas cuya relevancia propician la modelación de conductas coherentes, capaces de reconocer y respetar la diversidad que forma parte de su propio contexto de convivencia (Brandoni, 2017; Lipovestsky, 2000; Morales, 2018).

Esta posición refiere a la sensibilidad especial que le permite a la persona orientada compartir sus sentimientos con autenticidad, así como percibir las necesidades del otro mediante el manejo de competencias pro-sociales como la empatía, el altruismo y el respeto, requisitos fundamentales para establecer relaciones de ayuda y de cooperación que favorezcan el tratamiento de situaciones complejas. En atención a lo expuesto, Rogers (1996) asume que la orientación como acción educativa consiste en propiciar que la persona logre tener "contacto con problemas reales, a partir de los cuales aprender, evolucionar y descubrir en un intento por fomentar la confianza y el desarrollo de las potencialidades del individuo" (p. 11).

Los planteamientos citados indican que orientar es una actividad propia de agente especializado, capaz de disponer su instrumental estratégico para promover el crecimiento integral del ser humano como la clave necesaria para fortalecer el autoconocimiento; según la posición de Rogers (1996), orientar se asocia con dinamizar las relaciones entre los participantes del acto educativo, al cooperar con la motivación y el impulso de tareas, proyectos personales y colectivos, así como con la construcción de un ambiente escolar saludable en el que existan vínculos fuertes que lleven a la integración de los diversos actores y al fomento de actitudes de cooperación, compromiso y responsabilidad, como habilidades sociales elementales para formar ciudadanos en el presente siglo. 
Esta perspectiva es igualmente compartida por Montero (2004) quien afirma que la orientación como proceso psicosocial, cuenta con el potencial para fomentar "el compromiso como condición necesaria para para trabajar en, con y para la consolidación de condiciones más saludables de vida" (p. 112). Según los postulados que defienden a la orientación educativa como herramienta socioeducativa con el potencial transformador, se trata de propiciar procesos motivacionales que lleven según expone González (2008) a la búsqueda y al cumplimiento de objetivos y la satisfacción de las necesidades de la persona orientada, las cuales incluyen "experiencias positivas, deseos, sentimientos, emociones, aspiraciones y propósitos que, de existir las condiciones adecuadas, dirigen e impulsan la actividad hacia determinadas metas, que al ser logradas traen consigo su realización" (p. 52).

En este sentido, Molina (2002) propone que orientar, como acción inherente al docente de todos los niveles, debe centrarse en atender todas las dimensiones del ser humano con el objetivo de favorecer el autoconocimiento, la definición de sí mismo como un ente dotado de "capacidades, gustos, intereses, motivaciones personales que deben ser conocidos y manejados para garantizar la estabilidad y el desarrollo emocional desde el cual propiciar relaciones familiares y sociales coherentes" (p. 2). Este cúmulo de bondades de la Orientación Educativa deja entrever su carácter dinamizador al atribuirle sentido y consistencia a lo que se considera valioso, digno, oportuno así como conveniente, tanto a nivel personal como social.

Frente a esta posición, González (2012) propone que el profesional en orientación debe entenderse como un agente de transformación y cambio para "los actores del centro educativo, al posibilitar la realización de actividades motivacionales en la que entran en juego el desarrollo del potencial humano y las habilidades necesarias para consolidar relaciones apropiadas con las demandas de su realidad" (p. 12). De esta afirmación se desprende que la actuación de quien orienta apunta hacia la formación para y a lo largo de la vida como cometido medular de la educación para la ciudadanía mundial; es decir, para la búsqueda recurrente y constante de mejores condiciones de convivencia y de desarrollo humano, como aspectos de los que debe participar a los demás integrantes del sistema educativo, con el objeto, según Montero (2004), de "acompañar, actuar y responder con acciones efectivas que potencien el equilibrio socioeducativo" (p. 113).

Lo anterior, desde el punto de vista educativo, puede interpretarse como un compromiso académico con trascendencia al ámbito personal, pues el profesional en Orientación posee como atribución formar individuos con la motivación para realizar ajustes y adaptaciones a las necesidades propias y de su entorno, con el propósito facilitar soluciones efectivas. Para Méndez, Tesoro y Tiranti (2006), lo expuesto define líneas de acción enfocadas en "el abordaje de situaciones conflictivas, la propuesta de técnicas para el mejoramiento de las condiciones de aprendizaje, así como lo concerniente a problemas de estudio o de conducta, personales o relacionales" (p. 8).

Se trata de propiciar en el sujeto el descubrimiento de sí mismo, de las cualidades académicas y personales, de sus propias preferencias y potencialidades, así como de aquellas áreas que ameritan ejercitarse para responder de manera competente a los obstáculos, sin asumir la frustración como una respuesta continua que pudiera retrasar su proyecto de vida. Tal responsabilidad coincide con la propuesta de Bordón (2005), para quien el profesional en Orientación tiene atribuciones como "fomentar de manera continuada, amplia y variada el desarrollo de habilidades y competencias, nuevas actitudes y conocimientos que favorezcan la definición de sus objetivos como ser humano" (p. 2).

Por lo tanto, la acción orientadora, según Torres (1999), es una actividad imprescindible que le permite al estudiante proveerse del instrumental teórico para actuar de manera autónoma frente a las adversidades, asumiendo una actitud abierta y flexiva que le coopera con el manejo de "la creatividad, la receptividad al cambio y la innovación, la versatilidad en el conocimiento, anticipación y adaptabilidad a las situaciones cambiantes, capacidad de discernimiento, actitud crítica, así como la identificación y la solución de problemas" (p. 3). Estos cometidos indican que la orientación no se restringe exclusivamente a la 
atención individualizada, sino que espera del proceso la emergencia de nuevos modos que le permitan a la persona interactuar, dialogar y actuar en su contexto cotidiano, con el compromiso necesario para "proceder con conciencia, el sentimiento de responsabilidad con respecto al trabajo y los objetivos del grupo social al que pertenece" (Montero, 2004, p. 213).

De la posición anterior, puede inferirse que el profesional de la orientación en esta área es visto como un mediador socioeducativo capaz de ofrecer alternativas y posibles vías para la resolución de conflictos educativos, lo que implícitamente define su tendencia a la promoción de estrategias fundadas en la cultura de paz, en la comunicación y el diálogo como instrumentos al servicio de los actores educativos, quienes deben apropiarse de sus bondades para hacer frente a las controversias grupales. Se trata de una persona con la disposición y el compromiso, así como con el arsenal teórico y técnico necesario para estrechar vínculos de confianza y empatía como parte de las relaciones de ayuda que se deben dar en el escenario educativo.

A partir de lo anterior, Molina (2002) manifiesta que parte de las funciones de la persona que orienta se relaciona no solo con el empoderamiento, el accionar estratégico y su capacidad para motivar como parte de las competencia que definen su carácter dinamizador del proceso educativo, sino que además, con posibilitar que las personas asuman con autonomía "la toma de decisiones efectivas, la resolución de problemas personales y sociales, así como brindar asesoría en materia escolar y extraescolar" (p. 1). La afirmación deja entrever que el campo de acción del profesional de la orientación trasciende la atención personalizada y educativa, lo posiciona como un agente con las competencias para ofrecer acciones de intervención no solo en el contexto escolar, sino en el asesoramiento oportuno para el desarrollo comunitario, posibilitando la transformación inteligente de los obstáculos y limitaciones que pudieran emerger como resultado del dinamismo y la confluencia de intereses imperante.

Para Colls y otros (1998), lo expuesto implica propiciar en la persona orientada la comprensión del mundo y sus problemas, las dificultades y los modos como se pueden sortear con disciplina, reflexividad y actitud estratégica las adversidades que emergen de su propia realidad; ante este panorama, es necesario formar un ciudadano capaz de asumir "un buen desempeño individual y la autogestión como requerimientos para responder a las tareas y a los compromisos mediante el uso la escogencia de aquellas estratégicas que por su efectividad representan maneras coherentes de realizar intervenciones con beneficios tanto personales como colectivos" (p. 7). Esta posición es igualmente compartida por la psicología comunitaria, desde la que se asume que orientar se relaciona también con la concientización, el sentido de pertenencia y el activismo, como condiciones que sostenidas en el tiempo favorecen el accionar comprometido, planificado y reflexivo sobre las situaciones conflictivas.

El proceder citado requiere, entre otras cosas, del ofrecimiento de asistencia especializada consistente en preparar a la persona para la vida, para el encuentro consigo mismo y con los agentes que forman parte de su realidad, para lo cual es necesaria la construcción de acciones sistemáticamente organizadas y de técnicas sobre las cuales coadyuvar con el progreso de áreas importantes como lo son la dimensión profesional, académica, psicológica y social. Lo expuesto, visto desde los planteamientos de Tyler (1978), no es más que promover el autoconocimiento que le permita al ser humano "desarrollar su potencial humano como condición elemental para responder a sus propios intereses y del mundo del que hace parte" (p. 87).

Lo anterior refiere a los postulados del desarrollo humano, entre los que se propone que orientar consiste en confrontar a la persona con su realidad, su entorno inmediato, sus condiciones de vida, como dimensiones asociadas a la configuración de conductas que luego harán parte de su rol y de la posición que ocupará a nivel social. Esta relación de ayuda propone acercar a quien se orienta a la identificación de los escenarios y al desempeño de posibles roles; abordar estos aspectos, para Bronfenbrenner (1987), representa puntos sobre los que el profesional de la orientación debe focalizar sus esfuerzos, 
pues identificar los roles tiene "un poder casi mágico para modificar cómo se trata a una persona, cómo se actúa, lo que se hace y, por lo tanto, deducir lo que piensa y siente" (p. 26).

En suma, orientar en un siglo convulsionado por los cambios y la incertidumbre demanda procesos de intervención que se adecúen a las necesidades particulares y colectivas de la persona; es decir, atender todas sus dimensiones mediante el ofrecimiento de estrategias de exploración, de reconocimiento de potencialidades y capacidades como puntos fuertes de los que depende el desarrollo de procesos psicológicos como la autoestima, el autoconcepto y la identidad. Lograr el nivel de equilibrio en el ser humano alude, entre otros aspectos, a la disposición de quien orienta para construir escenarios de apoyo (familia, grupo de pares, entre otros) que presten ayuda, cuidado, seguridad y calidad de vida.

\section{PERFIL DEL PROFESIONAL DE LA ORIENTACIÓN}

El compromiso educativo y social de la orientación ha dado durante las últimas décadas un giro significativo, pues la emergencia de situaciones conflictivas como la discriminación, el consumo de sustancias, la violencia y la agresión, la disfunción y la desintegración familiar, se han convertido en problemas socioeducativos que por sus implicaciones directas en el proceso evolutivo y en el desarrollo del potencial humano, sitúan al profesional de la orientación como agente dinamizador, capaz de ofrecer asesoramiento estratégicos, impulsar acciones y revitalizar la transformación de los miembros de la sociedad (Bronfenbrenner, 1987; Montero, 2004; Morales, 2018).

En este sentido, definir el perfil del profesional de la orientación requiere la integración de funciones que van desde la atención especializada a nivel grupal e individual, el abordaje de problemas sociales y la resolución de conflictos, hasta la conducción de comunidades, la cohesión de esfuerzos y la consolidación de procesos motivacionales capaces de potenciar la consecución de objetivos comunes que determinan la construcción de espacios pacíficos, idóneos y enriquecedores para el desarrollo humano. De este modo, la vocación al servicio toma especial trascendencia, pues quien orienta debe estar dotado de la sensibilidad y el compromiso con el bienestar integral de las personas, debido a que socialmente se le concibe como un interventor benevolente, acompañante, asesor y guía.

En esta misma línea de pensamiento, Cruz y Olvera (2014) proponen que guiar representa un aporte propio de la orientación, que implícitamente refiere a motivar en el estudiante la asunción de riesgos controlados, de cambios e innovaciones como demandas que determinan "su formación académica y para que la que requieren la adquisición de hábitos y técnicas que faciliten su preparación, las toma de decisiones, así como el manejo de los problemas familiares y sociales que permean las relaciones humanas" (p. 2).

De este modo, las funciones del profesional de la orientación se enfocan en generar relaciones de acompañamiento educativo en las que el estudiante y demás actores educativos y sociales, logren mitigar la soledad y la incertidumbre que se genera al enfrentar las exigencias de cada etapa de la vida; es decir, aquellas necesidades que por su impacto son difíciles de procesar y entender y de las que muchas veces va a depender el correcto desarrollo de la personalidad como requerimiento para constituirse como un ser funcional (Gamboa y Sainea, 2017; Ponce y otros, 2018).

De esta manera, se puede decir que la persona encargada de orientar se concibe como un especialista con las competencias personales y profesionales de las que depende la atención de todas las dimensiones del ser humano dentro y fuera del sistema educativo, proveyendo, a través de relaciones de ayuda, la prevención de problemáticas que pudieran imposibilitar el efectivo desarrollo del potencial del ser humano (Bisquerra, 2005). A la posición citada se han agregado otros elementos que definen el perfil de la persona que orienta, a quien se piensa como portador de conocimientos teóricos así como del manejo 
metodológico necesario para promover acciones preventivas, las cuales aplicadas sistemática, continua y procesualmente cooperan con el desarrollo de las diversas dimensiones del ser humano (Arrieta, 2012; Vélaz, 2008).

En palabras de Corkille (1970) la persona que se dedica a la tarea de orientar, en tiempos complejos como los que atravesamos, debe contar con el instrumental estratégico y teórico para fomentar el desarrollo de la autoestima con el propósito de fortalecer la autoimagen y el autoconcepto de la persona, sin dejar de atender la repercusión de estos aspectos en "el manejo de sus sentimientos, el desarrollo de la creatividad, así como un desarrollo mental coherente que favorezca la posibilidad de convertir en realidad sus objetivos y, por ende, sentirse contentos de ser quienes son " (p. 15).

Por su parte Molina (2002) esgrime que la orientación educativa exige de quien se integra a su práctica, la disposición y la calidez humana para ofrecer servicios de atención especializada no solo en lo que refiere a necesidades educativas, sino en otras áreas como la configuración de "relaciones interpersonales coherentes y apropiadas en las que el individuo consiga satisfacer sus expectativas, objetivos y motivaciones que emergen en cada etapa del desarrollo del individuo" (p. 10). Montero (2004) al respecto indica que el profesional de la orientación debe ser capaz de propiciar acciones sinérgicas, que dinamicen el contexto educativo y comunitario, lo que implica sensibilizar para asumir el "compromiso en función de valores relativos a la justicia e igualdad sociales, a los derechos humanos, a los intereses y las necesidades de las comunidades y, fundamentalmente, al respeto del otro" (p. 114).

Lo anterior significa acompañar al estudiante para que logre valorar sus experiencias, sus vivencias personales y asumirlas responsablemente atendiendo a las exigencias propias de su proceso evolutivo. Frente a esto, la persona que orienta debe motivar la atribución de significados y la consolidación de metas importantes a través de un accionar sustentado en la intención, la disciplina y la dedicación. Según expone Rogers (1998) desde la psicología humanista, una atribución de quien orienta es guiar al ser humano a la "exploración de posibles vías sobre las que pudiera trabajar, valiéndose de esfuerzos disciplinados para lograr cometidos que por su importancia hacen al individuo funcional y lo revisten de la confianza necesaria para aprovechar el aprendizaje que entrañan los problemas y las situaciones adversas" (p. 10).

Lo expuesto puede interpretarse como un proceder activo que favorece la atención integral de la persona y de los aspectos fundamentales de los que depende la construcción de una identidad propia, la configuración de un personalidad equilibrada y la consistencia en sus propósitos de vida, como elementos medulares de los que dependerá en mayor o menor medida la realización personal y, como consecuencia, desarrollar las competencias socioemocionales necesarias para responder satisfactoriamente a las exigencias que la sociedad ha establecido para convivir positivamente. Esta postura desde el constructivismo implica llevar progresivamente a los actores educativos a constituirse en sujetos funcionales capaces de emplear sus habilidades sociales para participar de la vida colectiva y de la transformación de la misma.

En atención a lo anterior, parte de las atribuciones de quien orienta incluyen la promoción de la educación emocional, el autoconocimiento y la búsqueda del equilibrio socioemocional de la persona, para lo cual es necesario, según exponen Colls y otros (1998), "el logro de bienestar y el desarrollo general como necesidades que al ser satisfechas, traen consigo crecimiento en sus dimensiones sociales, incluyendo el ámbito personal y cognitivo como áreas que den cabida a la realización y a la estabilidad emocional" (p. 7). Montero (2004) reitera que las competencias del profesional de la orientación se enmarcan en "otorgarle dirección a los propósitos, consistencia a las metas y apoyo para la consolidación los proyectos de vida" (p. 115).

Esta actuación permite deducir que el perfil del profesional de la orientación aborda también la trasformación del interés personal en colectivo, la integración comprometida del ser humano hacia la 
cooperación y el altruismo, cometidos que, según la educación para la ciudadanía mundial (UNESCO, 2015), buscan formar personas con el potencial para resolver situaciones propias y de su espacio de actuación, mediante la práctica de valores como la empatía, el reconocimiento del otro y la cohesión de objetivos, a partir de los cuales se contribuye con la participación democrática, la toma de decisiones claras, inteligentes y coherentes, cuyas repercusiones se reflejen en la transformación propia y de los que son parte de su contexto. En palabras de Coll y otros (1998), la persona orientadora se describe como un agente con las competencias para "identificar problemas y articularlos con posibles vías de solución, valiéndose del procesamiento de información como requerimiento necesario para gestionar adecuadamente el cumplimiento de metas" (p. 4).

En apoyo a lo expuesto, Méndez, Tesoro y Tiranti (2006) proponen que el accionar de quien orienta debe enfocarse en aprovechar las actividades cotidianas para convertirlas en experiencias de aprendizaje que unidas a relaciones afectivas y de acompañamiento cooperen con la atención personalizada como medio para favorecer el desarrollo de "la autonomía y la responsabilidad para actuar de manera idónea en el mejoramiento de la calidad de vida propia y de terceros, preparándose con ello para integrarse a la sociedad" (p. 12). Para la psicología comunitaria la promoción del compromiso social constituye un aporte necesario para motivar la acción y la sensibilidad hacia los problemas que condicionan la convivencia y que requieren la unificación de esfuerzos y la cohesión de voluntades para generar procesos de renovación social (Montero, 2004).

La posición señalada exige, desde el escenario educativo, fomentar competencias sociales y habilidades cognitivas que posibiliten el ejercicio de relaciones interpersonales positivas en las que se promuevan elevados niveles de afectividad y altruismo, como aspectos determinantes de confianza capaces de movilizar los intereses grupales e individuales hacia el uso de la creatividad como mecanismo esencial para ejercitar la innovación dentro de los procesos de aprendizaje (Hernando, Juidías y Soto, 2005; Rogers, 1996). Estas cualidades del profesional de la orientación refieren a su compromiso con la satisfacción de necesidades de las personas que, por su dificultad para integrarse y responder a las exigencias sociales, requieren atención y apoyo personalizado para aflorar su potencial.

Desde esta perspectiva, la persona que orienta se constituye en un actor educativo con elevado compromiso socioeducativo que trasciende la dimensión académica al posibilitar, según Molina (2002), que el individuo logre "su desarrollo integral como requerimiento que le revista de la capacidad para influir sobre contextos sociales más amplios y ofrezca respuestas innovadoras a las demandas sociales" (p. 8). Lo expuesto describe a una persona con un liderazgo definido, activo y participativo, capaz de movilizar sus habilidades para transformar su contexto de manera significativa.

En esta misma línea de pensamiento, Aceves y Simental (2013) asumen que el profesional de la orientación representa, para el sistema educativo, el agente posibilitador de los medios para "Ilevar al sujeto a conseguir información sobre sí mismo, a identificar sus necesidades, así como tomar decisiones como aspectos fundamentales dentro del desarrollo de su proyecto vital" (p. 3). Las apreciaciones dejan entrever que orientar consiste en acompañar a las personas en el proceso de exploración de sus capacidades, habilidades y destrezas a través de las cuales logran sus objetivos, metas personales y profesionales.

Para las autoras antes mencionadas, quien orienta debe ser capaz de ofrecer servicios de orientación que integren aspectos elementales para el desarrollo de las dimensiones de la vida humana, dentro de las que se incluyen el manejo de situaciones relacionadas con la ansiedad, el afrontamiento de problemas vinculados con la identidad y la autoestima, el manejo del estrés y sus implicaciones, las dificultades para con el manejo de contenidos académicos cuyo especialización y complejidad ameritan del acompañamiento, así como la puesta en práctica de estrategias de aprendizaje.

A modo de complemento, por el conocimiento científico que maneja el profesional de la Orientación, le es posible fomentar relaciones interpersonales y el uso de habilidades sociales como herramientas al 
servicio de la formación de una personalidad coherente, sensible y equilibrada que le permita manejar de manera flexible los errores y problemas cotidianos, entendiéndolos como parte de las experiencias que se deben vivir para poner a prueba la resiliencia como actitud indispensable para enfrentar la frustración.

Para Solé (1998), el acompañamiento del orientado constituye una condición fundamental para la consolidación de actividades en las que se minimicen las posibilidades de incurrir en situaciones poco provechosas y, por el contrario, contribuyan con la "realización de un itinerario junto con el profesional en Orientación, en el que se establezcan acciones ordenadas enfocadas hacia la consecución de una meta sin tropezar" (p. 5). Siguiendo a la autora, la orientación intenta acercar al sujeto a situaciones hipotéticas en las que sea capaz de realizar ensayos recurrentes que funjan como simulacros que deriven en la preparación para la vida, para los retos y las vicisitudes desde una actitud positiva dada al crecimiento personal.

Otras de las atribuciones de quien orienta, consiste en enseñar al ser humano, según expone Solé (1998), a apropiarse de las herramientas para regular su propia actividad, con el propósito de adaptarlo progresivamente "al carácter dinámico de la realidad, a la cual deberá aplicar operaciones mentales que le permitan seleccionar, evaluar, persistir o abandonar determinadas acciones para llegar a conseguir las metas que se propone" (p.5). Propiciar este nivel de compromiso y disciplina exige que las personas identifiquen su potencial y la responsabilidad que deberán asumir tanto en la transformación de su realidad como en la búsqueda de su bienestar.

En palabras de Torres (1999), orientar como un proceso inherente al rol docente tiene como funciones "lograr que los estudiantes aprendan de sus vivencias, recreando y reconstruyendo los contenidos con la finalidad de adecuarlos a las necesidades propias de cada contexto" (p.2). Esta disposición hacia el aprendizaje como un proceso permanente indica que su compromiso académico le guía al aprovechamiento de cada experiencia y actividad educativa, a partir de las cuales construir conocimiento valioso desde el que le sea más accesible participar significativamente en el ejercicio de la ciudadanía.

Al respecto, Maturana (1990) señala que la educación implícitamente posee como funciones el orientar y formar para el desarrollo óptimo de la ciudadanía; es decir, sensibilizar en lo referente a la responsabilidad colectiva y social, así como contribuir con la creación de condiciones de solidaridad y bien común. A lo anterior agrega el autor que parte de las funciones de la persona que orienta, se enfocan en "la formación de un individuo competitivo ocupacional y laboralmente, capaz de integrarse a la transformación del contexto desde una actitud comprometida que le permite retribuir empáticamente a la comunidad" (p. 4).

Para Bruner (1995), el oficio del docente, además de generar las condiciones para que afloren competencias y habilidades, también persigue orientar a la persona para que se apropie de los valores socialmente aceptados, así como y del reconocimiento de "ciertos patrones básicos que los sujetos conocen de manera implícita o por la intuición, pero que requieren ser subrayados en forma explícita, entre los que se pueden destacar: la reciprocidad, el intercambio y la cooperación como mediadores de las relaciones sociales" (p.8). Se trata de desarrollar el sentido de pertenencia y de identidad como elementos sobre los que se sustente la construcción de espacios cohesionados, organizados e integradores, en los que se permita la participación activa, la integración y la responsabilidad social.

Otras perspectivas educativas provenientes de la educación para la ciudadanía mundial (UNESCO, 2015), proponen que los servicios de orientación como actividades de ayuda y asesoramiento deben producirse a lo largo del tiempo, es decir, desde los primeros contactos con el escenario educativo hasta niveles en los que el individuo logra desarrollar habilidades sociales y cognitivas para actuar responsablemente. Ello implica, según refieren Swartz y otros (2008), el "ofrecer las alternativas para gestionarse, controlarse y modificarse a sí mismo a través de acciones sistemáticamente organizadas que les permitan pensar de manera independiente" (p. 13). 
Al respecto Bisquerra (2009) propone que los servicios de asesoría, como parte de las funciones de la persona que orienta, deben perseguir, entre otros objetivos, que el ser humano consolide sus "competencias emocionales para que la persona desarrolle una ciudadanía activa, efectiva y responsable que propicien la adaptación al contexto social y un mejor afrontamiento a los retos que le plantea la vida" (p. 147). Desde esta perspectiva, la orientación educativa se entiende como el medio para consolidar el bienestar individual, la salud integral y el bien común, como condiciones necesarias para configurar relaciones interpersonales positivas que le sirvan de apoyo a quien es guiado para la construcción de escenarios idóneos para la convivencia.

Para lograr estos cometidos, se toma como referente a Bisquerra (2009) en cuanto a las funciones que definen al profesional de la orientación como agente protagónico dentro del escenario educativo. Las mismas se detallan a continuación:

1. Fomentar en el ser humano la revisión e identificación de sus potencialidades y fortalezas, con el propósito de definir de manera efectiva su propio autoconcepto, autopercepción y autoestima.

2. Promover el uso de la automotivación como estrategia para impulsar el logro de objetivos personales. Ello significa dejar de depender de factores externos para desarrollar una actitud autónoma que le permita operar sobre la prosecución de sus metas y de su propio proyecto de vida.

3. El manejo de la autoeficacia emocional como herramienta para construir responsablemente su percepción de la realidad y el rol que juega dentro del contexto social. Esta competencia implica la realización de ajustes emocionales que le permitan accionar sobre sus metas y objetivos.

4. El desarrollo del sentido de la responsabilidad, que oriente al ser humano a asumir posición positiva y autónoma frente a las exigencias del contexto, entendiéndose como persona a la que le asisten no solo derechos, sino obligaciones.

5. La asunción de una actitud positiva frente a las adversidades, la cual implica el desarrollo de habilidades para evaluar, comprender y definir, a partir de situaciones complejas y difíciles, posibles alternativas y oportunidades como evidencia de su optimismo ante las adversidades que se le presentan cotidianamente.

6. El uso de la resiliencia como aquella competencia para enfrentar los problemas desde una posición activa, autónoma y responsable, mediante respuestas necesarias para afrontar con éxito los cambios emergentes.

En correspondencia con lo expuesto, Newman, Griffin y Cole (1991) señalan que las funciones de quien orienta, desde una perspectiva amplia, significan guiar y asesorar para el logro y consolidación de las competencias socioemocionales, así como las habilidades sociales como procesos psicológicos fundamentales para establecer relaciones interpersonales con un elevado nivel de funcionalidad, y desde las cuales le sea posible realizar interacciones positivas, en las que participen la responsabilidad y la empatía social como valores encargados de cohesionar los intereses que vehiculizan la integración grupal como medio para lograr objetivos comunes (Brandoni, 2017; Maturana, 1990).

En suma, la orientación como un componente de la actividad educativa, debe entenderse como un proceso al servicio del crecimiento tanto personal, cognitivo, socioemocional, efectivo y social, con la finalidad de cumplir con cometidos fundamentales como la creación de escenarios ricos en motivación que propicien en el individuo el desarrollo de actitudes de cooperación, de habilidades empáticas y de competencias para cohesionar grupos y unificar esfuerzos; estrategias que por su importancia permiten la prevención de situaciones conflictivas que pudieran convertirse en obstáculos para optimizar las condiciones de la vida humana. En este sentido, el perfil de quien orienta debe contar con las competencias profesionales y personales que favorezcan procesos de intervención efectivos y enfocados en la transformación de la vida social. 


\section{CONCLUSIONES}

Como se ha señalado, la orientación constituye un proceso de apoyo y asesoramiento capaz de trascender el escenario educativo y social, así se constituye en un modo para potenciar el desarrollo integral del ser humano. Por tanto, el rol del profesional de la orientación como agente dinamizador gira en torno a la construcción y transformación de las condiciones de vida desde un enfoque holístico, en el que se atienden las dimensiones cognitivas, afectivas, emocionales y sociales, que le permitan a la persona integrarse competitivamente en la gestión de sí mismo y de su contexto, y que le demanda el ejercicio de valores como la libertad, la justicia, la dignidad y el respeto como ejes que por sus implicaciones sociales y educativas contribuyen con el reconocimiento del otro, así como con la reivindicación de sus derechos.

Los compromisos citados definen a la persona que orienta como un agente dotado de la sensibilidad especial, al que le acompaña el compromiso social y formativo de promover la corresponsabilidad entre los actores del proceso educativo, de quienes se espera el desarrollo de convicciones en favor de la resolución pacífica de conflictos y el manejo del diálogo como instrumentos fundamentales para la consolidación de escenarios en los que prime la igualdad de condiciones, de oportunidades y el desarrollo para todos sus integrantes.

Para lograr tales propósitos, la función del profesional de la orientación debe trascender de la acción psicopedagógica a la creación de relaciones de apoyo y de asesoramiento a través de las cuales la persona consolide competencias emocionales y personales, así como habilidades sociales que apunten hacia la erradicación del individualismo y, en su lugar, se posibilite la configuración de relaciones altruistas, de cooperación y de reciprocidad como garantes de funcionabilidad social. Por tal motivo, es posible afirmar que orientar en el siglo XXI implica el ofrecimiento de alternativas de asistencia socioeducativa, mediante las cuales facilitar la autorrealización, la satisfacción de necesidades y el crecimiento personal.

Es posible deducir que es necesario definir la orientación como un proceso inherente a un profesional con la calidad humana y académica que, en sentido estratégico, logre construir y aplicar acciones de intervención no solo en el escenario educativo, sino en el contexto social y comunitario. Lo expresado implica comprender que las relaciones de ayuda, apoyo y asesoramiento constituyen medios importantes para consolidar actitudes positivas y comportamientos oportunos que permiten el funcionamiento institucional, familiar y colectivo, las cuales garantizan que las nuevas generaciones se preparen para enfrentar dificultades, riesgos y los conflictos que recurrentemente emergen de una sociedad que tiende a complejizarse a pasos acelerados.

Por consiguiente, las relaciones de ayuda y guiatura se precisan como actividades inherentes a la orientación para y a lo largo de la vida (Maturana, 1990; Torres, 2006) proceso que persigue el logro de objetivos importantes como: la construcción de experiencias que cooperen con el desarrollo integral de la personalidad, la creación de escenarios idóneos para el encuentro consigo y con otros, la formación en valores como condición indispensable para la convivencia social, la educación para la paz, así como para el reconocimiento de la diversidad. Estos cometidos apuntan, entre otras razones, a propósitos generales y globalmente aceptados por la educación para la ciudadanía mundial, los cuales giran en torno al tratamiento del ser y de sus potencialidades, de las que se esperan la consolidación de respuestas altruistas, empáticas y solidarias favorecedoras de la construcción de contextos equilibrados que permitan la emergencia de relaciones humanas cónsonas con la convivencia, el bien común y el respeto.

En síntesis, acompañar y brindar asesoramiento en medio de una era saturada de situaciones conflictivas, caos social y la aparición recurrente de problemas complejos, exige del profesional de la orientación, el despliegue de competencias personales y el manejo de habilidades estratégicas que coadyuven con la creación de experiencias significativas y la generación de cambios sustanciales adecuados a las 
necesidades individuales y sociales del ser humano. A su vez, demanda integrar con mayor fuerza las actividades y funciones propias del profesional como agente con el potencial de prevenir situaciones nocivas, realizar intervenciones oportunas, identificar dificultades y atenderlas, así como facilitar relaciones de ayuda que le permitan la integración del ser humano, la escuela, la familia y el contexto social, con el propósito de unificar esfuerzos que posibiliten sortear con efectividad los cambios que emergen de la convivencia humana.

\section{REFERENCIAS}

Aceves, Y., y Simental, L. (2013). La orientación educativa en México. Su historia y perfil del orientador. Revista Pilquen. Sección Psicopedagogía • Año XV • No 10, 2013, pp.1-10.

Arrieta, B. (2012). Orientación educativa y orientadores educativos en el Estado de México; un análisis de dos casos. Rev ista Electrónica de Psicología Iztacala 15, (1), pp.55-79.

Barra, E. (1998). Psicología social. Universidad de Concepción.

Bisquerra, R. (1996).Orígenes y desarrollo de la orientación psicopedagógica. Madrid: Narcea.

Bisquerra, R. (2009). Psicopedagogía de las emociones. Madrid: Editorial Síntesis.

Bisquerra, R., y Pérez, N. (2007). Las competencias emocionales. Educación XXI, pp. 61-82.

Bordón (2005). Revista de orientación pedagógica. Vol. 57, № 3, pp. 297-314.

Brandoni, F. (2017). Conflictos en la escuela: manual de negociación y mediación para docentes. Buenos Aires: Universidad Nacional de Tres de Febrero.

Bronfenbrenner, U. (1987). La ecología del desarrollo humano. Barcelona: Paidós.

Bruner, J. (1998). Desarrollo cognitivo y educación. Madrid: Ediciones Morata.

Camps, V. (2000). Los valores de la educación. Madrid: Editorial Anaya.

Coll, C., y et al. (1998). El constructivismo en el aula. Barcelona: Editorial Graó.

Corkille, D. (1970). El niño feliz su clave psicológica. Barcelona: Granica Editor.

Cruz, S y Olvera, G. (2014). Acciones de orientación educativa y vocacional en la UNAM. IV Conferencia Latinoamericana sobre el abandono en la educación superior, pp.1-8.

Daros, W. (2009). El entorno social y la escuela. Rosario: Editorial Artemisa.

Freire, P. (2002). Educación y cambio. Editores Buenos Aires. Disponible en http://derechoepja.org/wpcontent/uploads/2015/05/freire-paulo_educacicion-y-cambio.pdf

Galeano, E. (1988). La escuela del mundo al revés. Madrid: Siglo XXI.

Galagovsky, L. (1993). Hacia un nuevo rol docente. Buenos Aires: Editorial Troqvel.

Gamboa, S y Sainea, C. (2017). Orientación educativa: una mirada a las representaciones sociales del orientador y su práctica en la escuela. Revista Cambios y Pertinencias, Vol. 8 № 2, julio-diciembre, pp. 337-378.

García, L y González, N. (2010). Competencias básicas. Tutor en educación superior: el desafío de un a construir. Congreso Iberoamericano de Educación Metas del siglo XXI, pp. 1-7. Buenos Aires: Universidad de Buenos Aires.

Gardner, H. (1996). La mente no escolarizada. Cómo piensan los niños y cómo deberían enseñar las escuelas. Buenos Aires: Editorial Paidós.

González, M. (2012).El rol del orientador en el siglo XXI. ACLPP Informa. N²7, pp.12-15.

González, D. (2008). Psicología de la motivación. Cuba: Editorial Ciencias Médicas. 
Hernando, Juidías y Soto (2005). Estudio de los roles y funciones del orientador de educación secundaria a través de la técnica del grupo de discusión. Revista de Psicología. Vol. 2, núm. 1, pp. 673-683.

Huici, C y et al. (2012). Psicología de los grupos. Madrid: Ediciones Universidad Nacional Educación a Distancia.

Illich, I. (1985). La sociedad desescolarizada. Ciudad de México: Editorial Joaquín Moritz.

Lipovestsky, G. (2000). La era del vacío. España: Editorial Anagrama.

Maslow, A. (1954). Motivación y personalidad. Nueva York: Harper and Row.

Maturana, H. (1990). Emociones y lenguaje en educación política. Colección HACHETTE/COMUNICACIÓN CED.

Méndez., H, Tesoro, Ry Tiranti, F. (2006). El rol del tutor como puente entre la familia y la escuela. Argentina: Editorial Distribuidora Lumen SRL.

Molina, D. (2002). Concepto de orientación educativa: diversidad y aproximación. Revista Iberoamericana de Educación, pp. 1-22.

Morales, J. (2018). La violencia en escenarios educativos: un acercamiento multidisciplinario para su comprensión. Innovaciones Educativas · Año XX · Número 29, pp. 81-94.

Newman, D., Griffin, P., y Cole, M. (1991). La zona de construcción del conocimiento: trabajando por un cambio cognitivo en la educación. Madrid: Ediciones Morata, S.A.

Novak, J., y Gowin, D. (1998). Aprendiendo a aprender. Barcelona: Ediciones Martínez Roca

Piaget, J. (2001). Psicología y pedagogía. Madrid: Editorial Booket.

Ponce, S., García, B., Islas, D., Martínez, Y y Serna, A. (2017). De la tutoría a la mentoría. Reflexiones en torno a la diversidad del trabajo docente. Revista Páginas de Educación. Vol. 11, (Núm. 2), 2018, pp. 215-235.

Rogers, C. (1989). El proceso de convertirse en persona. Barcelona: Editorial Paidós.

Rogers, C. (1996). Libertad y creatividad en la educación. Barcelona: Editorial Paidós.

Rogoff, B. (1993). El desarrollo cognitivo en el contexto social. Barcelona: Paidós.

Solé, I. (1998). Estrategias de lectura. Barcelona: Editorial Graó.

Swartz y et.al. (2008). El aprendizaje basado en el pensamiento. Cómo desarrollar en los alumnos las competencias del siglo XXI. Ediciones SM.

Torres, R. (1999). Nuevo rol docente: ¿qué modelo de formación, para qué modelo educativo. Madrid: Fundación Santillana.

Tyler, L. (1978). La función del orientador. México: Editorial Trillas.

UNESCO. (2015). Orientación y Desarrollo de Capacidades sobre Educación para la Ciudadanía Mundial en América Latina y el Caribe. Reporte Informativo. Santiago de Chile.

Vélaz, C. (2008). Competencias del profesor-mentor para el acompañamiento al profesorado principiante. Vol. 13, № 1, pp. 210-229.

Para citar este documento:

Morales, J. (2020). El rol del orientador como agente dinamizador del escenario educativo y social Revista Innovaciones Educativas. 22(32). Pp. 184-198. DOI: 10.22458/ie.v22i32.2903 